\title{
PENERAPAN ANALISIS KONTEN PADA POLA PENGEMBANGAN PARIWISATA HALAL BERBASIS MASYARAKAT DI GEOSITE LEMBAH SEMBALUN
}

\author{
Idham Kholid ${ }^{1}$, Akhmad Saufi ${ }^{2}$, Baiq Handayani Rinuastuti ${ }^{3}$ \\ ${ }^{1}$ Master of Management Program, Mataram University, Indonesia. \\ E-mail: kholid.idham1195@gmail.com \\ ${ }^{2}$ Faculty of Economics and Business, Mataram University, Indonesia. \\ E-mail:akh.saufi@omail.com \\ ${ }^{3}$ Faculty of Economics and Business, Mataram University, Indonesia. \\ E-mail:hrinuastuti@yahoo.com
}

\begin{tabular}{|c|c|}
\hline ARTICLE INFO & ABSTRACT \\
\hline \multirow{3}{*}{$\begin{array}{l}\text { Keywords: } \\
\text { Content Analysis, Halal Tourism, Pattern, } \\
\text { Participation, Geosite Lembah Sembalun }\end{array}$} & This study aims to find the results of content analysis in \\
\hline & determining the pattern of developing halal tourism \\
\hline & $\begin{array}{l}\text { based community in Geosite Lembah Sembalun. Data } \\
\text { collection was colledted through observation, in-depth }\end{array}$ \\
\hline \multirow{2}{*}{$\begin{array}{l}\text { Kata Kunci: } \\
\text { Analisis Isi, Wisata Halal, Pola, Partisipasi, } \\
\text { Geosite Lembah Sembalun }\end{array}$} & interviews and documentation. The results of this study \\
\hline & $\begin{array}{l}\text { obtained } 3 \text { categories and } 11 \text { themes through open and } \\
\text { axial coding processes. In this study, it is stated that the } \\
\text { pattern of developing halal tourism based community in }\end{array}$ \\
\hline \multirow{2}{*}{$\begin{array}{l}\text { How to cite: } \\
\text { Kholid, Idham., Saufi, Akhmad., Rinuastuti, } \\
\text { Baiq Handayani., (2020). Content Analysis } \\
\text { In Determining The Pattern of Developing } \\
\text { Halal Tourism In Geosite Lembah Sembalun. } \\
9 \text { (4a) JMM UNRAM, 68-80 }\end{array}$} & $\begin{array}{l}\text { Geosite Lembah Sembalun is spontaneous and induced } \\
\text { participation obtained from } 3 \text { categories of content }\end{array}$ \\
\hline & $\begin{array}{l}\text { analysis, namely community participation in } \\
\text { involvement phase, degree of participation and } \\
\text { community participation in developing halal tourism. }\end{array}$ \\
\hline $\begin{array}{l}\text { DOI: } \\
\text { http://dx.doi.org/10.29303/jmm.v9i4a.608 }\end{array}$ & $\begin{array}{l}\text { Penelitian ini bertujuan untuk menemukan hasil } \\
\text { analisis konten pada pola pengembangan } \\
\text { pariwisata halal berbasis masyarakat di gesoite }\end{array}$ \\
\hline \multirow{4}{*}{$\begin{array}{l}\text { Dikumpulkan } \\
\text { Direvisi } \\
\text { Dipublikasi }\end{array}$} & $\begin{array}{l}\text { lembah sembalun. Pengumpulan data dilakukan } \\
\text { melalui observasi, wawancara mendalam dan }\end{array}$ \\
\hline & dokumentasi. Hasil penelitian ini mendapatkan 3 \\
\hline & $\begin{array}{l}\text { kategori dan } 11 \text { tema melalui proses open dan axial } \\
\text { coding. Dalam penelitian ini dikemukakan bahwa } \\
\text { pola pengembangan pariwisata halal berbasis } \\
\text { masyarakat di Geosite Lembah Sembalun adalah } \\
\text { partisipasi spontan dan induced yang didapatkan } \\
\text { pada } 3 \text { kategori dari hasil analisis konten yaitu } \\
\text { partisipasi masyarakat dalam fase pelibatan, } \\
\text { tingkat partisipasi dan partisipasi masyarakat } \\
\text { dalam pengembangan pariwisata halal. }\end{array}$ \\
\hline & $\begin{array}{l}\text { Copyright (C) 2020. Idham Kholid, Akhmad Saufi, } \\
\text { Baiq Handayani Rinuastuti. All rights reserved. }\end{array}$ \\
\hline
\end{tabular}




\section{PENDAHULUAN}

Industri pariwisata adalah salah satu sektor penting yang menjadi pendorong pembangunan ekonomi global. Sektor ini memainkan peran penting dalam menyegarkan pertumbuhan ekonomi di banyak negara maju dan berkembang (Chaiboonsri \& Chaitip, 2008). Pariwisata menjadi dimensi vital dari integrasi global dan kegiatan perdagangan, karenanya, pariwisata menjadi sumber penghasilan terbesar di dunia (Jaafar., Shah., \& Marzuki., 2014). Di Indonesia, sektor pariwisata menjadi salah satu program prioritas pemerintah Indonesia yang menjadi nawacita pembangunan ekonomi nasional. Lombok, Indonesia merupakan salah satu destinasi wisata yang menjadi pembangunan super prioritas kepariwisataan nasional yang terdiri dari kawasan ekonomi pariwisata (KEK) dan kawasan strategis kepariwisataan nasional (KSPN) (Disbudpar, 2010). Lombok juga menjadi sepeluh destinasi yang dikembangakn sebagai destinasi wisata halal (IMTI, 2019). Dalam pengembangan pariwisata yang berkelanjutan di Lombok maka dibutuhkan partisipasi masyarakat. Karena dengan adanya partisipasi masyarakat dalam perencanaan dalam pengembangan pariwisata sampai pengawasan mampu meningkatkan aktivitas dan diversifikasi produk wisata sehingga berdampak positif ke masyarakat (Kurniawati., Hamid., \& Hakim (2018).

Zaini (2019) mengemukakan bahwa dalam pengembangan pariwisata halal di desa Sembalun Lawang Lombok Timur, masyarakat memiliki peran serta dalam membuat strategi pengembangan, pengelolaan objek wisata, pemandu, pengelolan homestay dan kesenian serta berimplikasi terdahadap kesejahteraaan masyarakat. Kemudian penelitian Tosun (1999) mengemukakan bahwa kosep partisipasi yang secara umum tidak sesuai dengan fakta di lapangan maka diperlukan pola partisipasi yang sesuai dengan kondisi di setiap destinasi dan kategori yang bisa di adaptasikan. Maka untuk melakukan pembangunan pola pengembangan maka dilakukan penelitian dengan menggunakan metode kualitatif dengan analisis konten. Penelitian kualitatif adalah penelitian yang datanya berasal dari hasil interview, dokumentasi yang di transformasi dalam kata - kata (Bengtsson, M., 2019).

Data penelitian kualitatif akan di interpretasikan untuk mendapatkan hasil namun dalam interpretasi terkadang mengalami kesalahan sehingga berdampak ke hasil penelitian (Catanzora, 1988). Oleh karena itu untuk mendapatkan hasil yang konfrehensif maka dalam penelitian ini menggunakan analisis konten sebagai alat analisis dalam melakukan interpretasi data untuk membangun pola pengembangan pariwisata halal berbasis masyarakat di Geosite Lembah Sembalun.

\section{KAJIAN PUSTAKA}

\subsection{Analisis Konten}

Krippendorff (2004) mendefinisikan analisis konten adalah teknik penelitian untuk membuat kesimpulan yang dapat direplikasi dan valid dari teks ke konteks penggunaannya. Downe-Wambolt (1992) menggarisbawahi bahwa analisis isi lebih dari proses penghitungan, karena tujuannya adalah untuk menghubungkan hasil dengan konteksnya atau dengan lingkungan di mana mereka diproduksi: analisis konten adalah metode penelitian yang menyediakan sistematik dan tujuan berarti untuk membuat kesimpulan yang valid dari verbal, visual, atau data tertulis untuk menggambarkan dan mengukur fenomena tertentu. Data tekstual dapat dalam bentuk verbal, cetak, atau elektronik dan dapat diperoleh dari tanggapan naratif, pertanyaan survei terbuka, 
wawancara, kelompok fokus, observasi, atau media cetak seperti artikel, buku, atau manual (Kondracki \& Wellman, 2002). Tujuan menggunakan analisis konten sebagai metode penelitian adalah untuk memberikan wawasan baru dan meningkatkan pemahaman tentang fenomena tertentu, dan untuk mendapatkan deskripsi fenomena yang lebih luas dan lebih ringkas, serta untuk mendeskripsikan dan mengukur suatu fenomena (Moldavska \& Welo, 2017). Metode analisis konten bisa digunakan pada penelitian kuantitatif dan kualitatif (Krippendorff, 2004; Berg, 2001). Analisis konten kuantitatif berawal dari penelitian media. Analisis konten kuantitatif yakni data dari text rubah menjadi persentasi atau jumlah kategori sedangkan analisis konten kualitatif berakar pada penelitian sosial yang dimana untuk analisis datanya berasal dari kata kata yang di tampilkan dalam bentuk tema yang akan di interpretasikan (Krippendorff, 2004).

Peneliti harus memilih apakah analisis tersebut merupakan analisis manifes atau analisis laten. Dalam analisis manifes, peneliti mendeskripsikan apa yang sebenarnya dikatakan informan, berada sangat dekat dengan teks, menggunakan kata-kata itu sendiri, dan mendeskripsikan apa yang terlihat dan jelas dalam teks. Sebaliknya, analisis laten diperluas ke tingkat interpretif di mana peneliti berusaha untuk menemukan makna yang mendasari teks, apa yang sedang dibicarakan teks (Berg, 2001; Catanzaro, 1988; DowneWambolt, 1992). Salah satu tantangan analisis konten adalah kurangnya resep atau standar umum untuk pelaksanaannya. Oleh karena itu, kualitas analisis konten telah dibahas secara luas oleh para peneliti. Dalam kasus analisis konten, istilah seperti validitas, reliabilitas, dan kepercayaan telah digunakan untuk menangani kualitas penelitian (Elo et al., 2014).

\subsection{Siklus Hidup Destinasi}

Untuk mengidentifikasi partisipasi masyarakat di siklus hidup destinasi maka penelitian ini menggunakan teori Tourism Area Life Cycle yang di kemukanan oleh Butler pada tahun 1980 tentang siklus hidup destinasi wisata dimulai dari exploration, involvement, development, consolidation, stagnation, decline dan rejuvenation. Analisis ini dilakukan agar pengelola dan pemerintah mengetahui posisi destinasi wisata sehingga kemudian dapat siapkan program pembangunan, pemasaran, carrying capacity dan pola partisipasi masyarakat dalam pembangunan pariwisata halal tersebut dapat ditentukan dengan tepat (Butler, 1980, 2011; Bagus, 2011).

Dalam penelitian Abdillah., Damanik., Fandeli., \& Sudarmadji (2015), dengan judul Perkembangan Destinasi Pariwisata dan Kualitas Hidup Masyarakat Lokal. Penelitian ini mengukur siklus hidup destinasi Pengandaran dan Palabuhan Ratu. Penelitian ini menggunakan konsep Butler (1980). Dengan hasil destinasi Pangandaran berada pada fase pertumbuhan dan Palabuhanratu berada pada fase konsolidasi. Diketahui dari penelitian ini menunjjukan bahwa terdapat hubungan positif antara perkembangan destinasi pariwisata dengan kualitas hidup masyarakat lokal. Hubungan terjadi dipicu oleh pertumbuhan jumlah wisatawan yang memberikan dampak berupa pekerjaan dan usaha. Alokasi hasil hasil usaha tersebut digunakan untuk menjamin kualitas hidup yang lebih baik terdiri dari empat aspek kualitas hidup berupa material, sosial, pribadi, dan spiritual.

\subsection{Tipologi Partisipasi}

Pada dasarnya community-based tourism (CBT) merupakan konsep pengambangan pariwisata yang dimana subjeknya ada masyarakat setempat yanga ada di destinasi tersebut. Bentuk dan implikasi partisipasi dalam pengembangan pariwisata masih dalam perdebatan (Tosun, 1999). Istilah partisipasi masyarakat sudah 
berkembang dan tersebar luas namun masih belum jelas bentuknya (Jamal and Getz 1995; Keogh 1990; Simmons 1994), dan menjadi ambigu (Law-Yone, 1982). Terkadang partisipasi dalam praktik pariwisata di interpresatasi dengan masyrakat sebagai pengelola dan menjadi subjek pariwisata.

Untuk mengetahui lebih detail tentang tipologi partisipasi masyarakat maka dalam penelitian ini akan menyajikan beberapa hasil penelitian terdahulu. Penelitian Tosun tahun 1999 dengan judul towards a typology of community participation in the tourism development process menemukan bahwa pengertian partisipasi masyarakat dalam pariwisata bersumber dari konsep umum partisipasi masyarakat dalam studi pembangunan dan dalam runaglingkup yang terbatas. Sehingga isolasi tersebut telah mengantarkan pada paradigma partisipasi masyarakat yang kaku dan sederhana. Ini dianggap satu bentuk dan memiliki validitas universal tanpa mempertimbangkan adanya keadaan yang berbeda di berbagai destinasi wisata.

Pretty tahun 1995 melakukan penelitian dengan judul participatory learning for sustainable agriculture mengemukakan ada tujuh tipologi partisipasi masyarakat yaitu manipulative participation, passive participation, participation by consultation, participation for material incentives, functional participation, interactive participation dan self-mobilization. Sedangkan penelitian Arnstein tahun 1969 dengan judul A Ladder of Citizen Participation mengemukakan ada delapan tiologi partisipasi masyarakat yaitu manipulation dan therapy masuk kategori non-participation, informing, consulation dan placation masuk kategori degrees of citizen tokenism serta parnteship, delegated power dan citizen control masuk kategori degrees of citizen power.

\subsection{Pariwisata Halal}

Terminologi pariwisata halal (halal tourism) merupakan terminologi yang menggabungkan dua kata yaitu pariwisata dan halal. Dalam kajian - kajian tentang pariwisata halal, istilah ini terkadang sulit dibedakan dengan istilah pariwisata islam (Islamic tourism) (Battour, Ismail, \& Battor, 2011; Henderson, 2009). Namun penggunaan Halal lebih tepat dari pada Islamic dalam produk dan jasa pada industri pariwisata (Battour \& Ismail, 2016). Sedangkan halal menurut Al-Qaradawi (2013) dalam bukunya yang berjudul 'The Lawful and the Prohibited in Islam' mengartikan halal sebagai sesuatu yang di izinkan. "That which is permitted, with respect to which no restriction exists, and the doing of which the law-giver, Allah, is allowed".

Untuk memperkuat kajian ini maka berikut hasil penelitian yang relevan dengan pengambangan pariwisata halal dibeberapa tempat. Penelitian yang di lakukan Kodir., Karim., \& Paksi, (2019) tentang pengembangan pariwisata halal di Jepang mengemukakan bahwa pengembangan pariwisata halal di Jepang dilakukan oleh Lembaga pariwisata nasional Jepang yaitu JNTO (Japan National Tourism Organization) dan Japan Travel Agency (JTA). Selain pemerintah ada juga peran sector swasta seperti Japan Tourist Bureau (JTB). Selain itu pemerintah juga di dukung oleh organisasi islam seperti Japan Halal Association (JHA), the Japan Halal Business Association's Nippon Halal Association (NAHA), dan the Halal Development Foundation Japan Incorporated.

Dalam praktik pariwisata halal di Jepang Lembaga pariwisata nasional atau JNTO membuat panduan untuk wisatawan muslim yang berkunjung ke Jepang. Memperkuat atribut dan hospitality terhadap wisatawan muslim seperti melakukan sertifikasi produk halal, menyiapkan makan halal, menyiapkan fasilitas ibadah baik di destinasi wisata maupun di transportasi umum (Kereta Api dan Bandara) dan tidak menyediakan minuman alkohol di beberapa hotel. 
Kemudian penelitian yang di lakukan oleh Nudiansyah (2016) tentang sertifikasi halal dan dampaknya terhadap pariwisata di Asia Tenggara: studi kasus pariwisata halal di Thailand mengemukakan bahwa pemerintah dalam hal pengembangan pariwisata halal melakukan sertifikasi produk halal untuk makanan dan minuman baik restoran dan hotel, menyiapkan fasilitas ibadah dan membuat aplikasi Thailand Muslim Friendly dimana wisatawan bisa menemukan restaurant halal, masjid, dan lain - lain. Selain aplikasi pengembangan pariwisata halal di Thailand juga di dukung sektor industry seperti travel agent, dimana terdapat travel - travel agent halal sudah berkembang dan membuat pusat wisata halal (halallivingthailand, 2014)

\section{METODE PENELITIAN}

Jenis penelitian yang digunakan dalam penelitian ini adalah penelitian kualitatif dengan pendekatan analisis konten dalam membangun pola pengembangan pariwisata halal berbasis masyarakat di Geosite Lembah Sembalu. Sebagai metode penelitian, ini merupakan cara sistematis dan obyektif untuk menggambarkan dan mengukur fenomena (Downe-Wamboldt, 1992; Schreier, 2012). Pada analisis konten terhadap tiga tahap analisis yakni tahap persiapan, organisasi, dan pelaporan hasil. Tahap persiapan terdiri dari pengumpulan data yang sesuai untuk analisis isi, memahami data, dan memilih unit analisis. Dalam pendekatan induktif, fase organisasi meliputi pengkodean terbuka, membuat kategori, dan abstraksi (Elo \& Kyngäs, 2008). Dalam analisis konten deduktif, fase organisasi melibatkan pengembangan matriks kategorisasi, di mana semua data ditinjau untuk konten dan dikodekan untuk korespondensi atau contoh dari kategori yang teridentifikasi (Polit \& Beck, 2012).

Matriks kategorisasi dapat dianggap valid jika kategori mewakili konsep secara memadai, dan dari sudut pandang validitas, matriks kategorisasi secara akurat menangkap apa yang dimaksudkan (Schreier, 2012). Pada tahap pelaporan, hasil dijelaskan oleh konten kategori yang menggambarkan fenomena menggunakan pendekatan yang dipilih (baik deduktif atau induktif). Namun, prosedur bertahap yang disajikan di sini tidak boleh ditafsirkan sebagai preskriptif karena tidak ada aturan sistematis untuk mengumpulkan dan menganalisis data karena hal yang utama dari semua prosedur analisis isi adalah pengurangan banyak kata menjadi sejumlah kategori yang lebih kecil (Klenke, 2008).

\subsection{Perencanaan}

Perencanaan dimulai dengan menentukan lokasi penelitian dan informan yang sesuai dengan rumusan masalah sehingga temuan di lapangan bisa menjadi instrument dalam pengembangan penelitian. Lokasi penelitian ini adalah Geosite Lembah Sembalun kecamatan sembalun di tiga desa yakni desa Sembalun Bumbung, Lawang dan Sembalun. Peneliti mengunakan teknik purposive sampling dalam proses penentuan informan (Meleong, 2018). Ini dilakukan untuk mencari informan sesuai dengan kebutuhan penelelitian. Informan yang digunakan adalah pelaku wisata, akademisi, tokoh masyarakat dan pemdes serta sekertaris dinas pariwisata Lombok Timur.

\subsection{Pengumpulan Data}

Metode dokumentasi, observasi dan wawancara menjadi metode utama pengumpulan data, seperti yang direkomendasikan oleh Jennings (2011). Penelitian ini menggunakan dua jenis data yaitu data primer dan data sekunder. Data primer didapatkan dari observasi dan wawancara di lapangan sedangkan data sekunder 
didapatkan melalui catatan atau dokumentasi perusahaan, sosial media dan situs web perusahaan. Dalam proses interview dilakukan dengan telepon karena dalam masa pandemi Covid-19 dan social distancing dilaksanakan sebagai upaya pencegahan penularan Covid-19. Jangka waktu pengumpulan data mulai Mei hingga Juli 2020. Pengumpulan data dilakukan melalui observasi, wawancara mendalam dan dokumentasi. Wawancara dilakukan dengan 13 informan, berkisar antara 15 sampai 45 menit. Proses dokumentasi dilakukan dengan mengumpulkan dokumen-dokumen terkait partisipasi masyarakat. Menurut Moleong (2011), dokumentasi adalah dokumen-dokumen yang dapat diakses oleh peneliti dari informan untuk menambah informasi data bagi penelitian seperti foto, catatan, bukti online (IG, Website dan FB).

Observasi merupakan kemampuan seseorang menggunakan pengamatannya melalui hasil kerja panca indera (Bungin, 2012). Pengumpulan data melalui observasi dilakukan tanpa mengajukan pertanyaan secara langsung pada subyek penelitian melainkan mencatat fenomena yang terjadi untuk memperoleh gambaran yang jelas. Observasi dilakukan dengan mengunjungi Geosite Lembah Sembalun dan melihat peraktik pariwisata halal berbasis masyarakat.

\subsection{Analisis Data}

Rekaman ditulis dan dianalisis menggunakan analisis konten. Analisis isi digunakan untuk menganalisis wawancara mendalam (Wann-Hansson, Hallberg, Klevsgård \& Andersson, 2005). Eriyanto (2011) menyebutkan tujuan analisis adalah untuk mendeskripsikan makna, aspek, dan karakteristik pesan dari responden. Dalam analisisnya, data diinterpretasikan dengan memberikan kode berupa kata-kata tertentu yang menunjukkan topik yang muncul dan membentuk tema serta kategori. Selanjutnya tema dikelompokkan ke dalam kategori berdasarkan kesamaan dan relevansi fokus dan konteks penelitian untuk membentuk konsep tertentu (Saufi, A., O'Brien, D., dan Wilkins, H. 2014).

Penelitian ini menggunakan open coding dan axial coding dalam proses analisinya. Open coding dirancang untuk mengekspresikan data dalam bentuk konsep awal. Dalam langkah proses pengkodean ini, kode awal bersifat sementara, komparatif, dan didasarkan pada data (Charmaz, 2006). Langkah selanjutnya dalam prosedur ini adalah mengkategorikan kode-kode ini dengan mengelompokkannya di sekitar fenomena yang terkait dengan data yang secara khusus relevan dengan pertanyaan penelitian. Kategori yang dihasilkan kemudian ditautkan ke kode yang sekarang lebih abstrak daripada yang digunakan pada langkah pertama. Sebuah teks dapat diberi kode baris demi baris, kalimat demi kalimat, atau paragraf demi paragraf, atau kode dapat dihubungkan ke seluruh teks. Axial coding mengikuti open coding sebagai langkah selanjutnya untuk menyempurnakan dan membedakan kategori yang dihasilkan dari open coding. Dari sekian banyak kategori yang bermula dari open coding, dipilihlah yang tampaknya paling menjanjikan untuk dielaborasi lebih lanjut (Klenke, 2008).

\subsection{Triangulasi}

Triangulasi merupakan teknik pemeriksaan keabsahan data yang memanfaatkan sesuatu yang lain. Hasil penelitian ditriangulasi menggunakan tiga mekanisme utama: (1) Temuan dikonfrontasikan dengan data hasil dokumentasi; (2) cek anggota; dan (3) Diskusi dengan para pelaku wisata yang memiliki keahlian di bidang pariwisata 


\section{HASIL DAN PEMBAHASAN}

Tujuan dari analisis ini adalah untuk membangun pola pengembangan pariwisata halal berbasis masyarakat di Geosite Lembah Sembalun. Penelitian ini menggunakan tabel coding untuk membantu mulai tahap pengkodean hingga tahap penarikan kesimpulan. Kode diurutkan ke dalam kategori berdasarkan bagaimana kode yang berbeda terkait dan ditautkan (Patton, 2002). Tujuan dasar dalam proses pengkodean adalah untuk mengatur teks yang besar menjadi konten yang jauh lebih sedikit kategori, yaitu reduksi data. Saat analisis berlanjut, kode tambahan adalah dikembangkan, dan skema pengkodean awal direvisi dan disempurnakan. Kategori mungkin didefinisikan berdasarkan pertanyaan penelitian dan/atau teori dan konstruksi yang mendasari. Berdasarkan hasil coding tersebut, dihasilkan 3 kategori dan 11 tema yang dapat dilihat pada tabel 1 dibawah ini:

Tabel 1. Frekuensi Tema

\begin{tabular}{|c|l|c|}
\hline \multicolumn{1}{|c|}{ Kategori } & \multicolumn{1}{|c|}{ Tema } & Frekuensi \\
\hline \multirow{4}{*}{ Partisipasi fase Pelibatan } & Perencanaan & 2 \\
\cline { 2 - 3 } & Pengelolaan & 5 \\
\cline { 2 - 3 } & Pengontrolan & 4 \\
\hline \multirow{3}{*}{ Tingkat Partisipasi } & Partisipasi aktif & 6 \\
\cline { 2 - 3 } & Partisipasi langsung & 2 \\
\cline { 2 - 3 } & Top-Down & 8 \\
\hline \multirow{3}{*}{$\begin{array}{c}\text { Partisipasi masyarakat dalam } \\
\text { pengembangan pariwisata halal }\end{array}$} & Homestay & 3 \\
\cline { 2 - 3 } & Trekking Organizer & 6 \\
\cline { 2 - 3 } & Pengelolaan Objek Wisata & 6 \\
\cline { 2 - 3 } & Promosi/TIC & 3 \\
\cline { 2 - 3 } & Ancillary/Kelembagaan & 2 \\
\hline
\end{tabular}

Sumber : Open dan axial coding

\subsection{Partisipasi pada fase pelibatan}

Hasil analisis konten yang dilakukan menemukan 3 tema yang berhasil dihubungkan menjadi 1 kategori yakni partisipasi masyarakat pada fase pelibatan. Ketiga tema ini saling berkaitan dalam pengembangan pariwisata di Geosite Lembah Sembalun. Mulai dari perencanaan, pengelolaan dan pengontrolan. Dengan adanya keterlibatan masyarakat dalam pengembangan pariwisata berdampak baik ke ekonomi masyarakat, meningkatkan kesejahteraan dan menjaga lingkungan sekitar. Fase pelibatan, masyarakat secara umum mendominasi kegiatan ekonomi dengan membangun usaha skala kecil, ditandai dengan kemampuan wirausahawan melakukan identifikasi peluang usaha (Saufi, et.al., 2014). Hal ini menggambarkan bagaimana masyarakat lokal menjadi subjek dalam mengembangkan pariwisata (Saufi, et al., 2014; Demartoto, 2018; Kanom dan Zazilah, 2019).

Dilakukannya analisis ini untuk mengetahui partisipasi masyarakat dari fase ke fase sehingga masyarakat mengetahui posisi mereka serta fase siklus destinasi wisata agar kemudian dapat melakukan peningkatan partisipasi dalam pembangunan, pemasaran dan carrying capacity dalam pembangunan pariwisata halal dapat ditentukan dengan tepat (Butler, 1980, 2011; Bagus, 2011). Selain itu analisis ini dilakukan untuk meninjau kembali kelayakan sebuah destinasi untuk membuat kebijakan dalam melakukan perbaikan secara sesuai lima aspek: keadilan, efektivitas, efisiensi, kredibilitas, dan integrasi Toth (dalam Bagus, 2011). 


\section{2. $\quad$ Tingkat partisipasi}

Kategori ini terdiri dari 3 tema yang membangunnya, partisipasi aktif, langsung dan top-down. Partisipasi aktif dan langsung memiliki frekuensi yang banyak dari pada top-down. Untuk mengetahui tingkat partisipasi masyarakat dalam mengembangkan pariwisata maka pada pembasahan ini menguraikan tentang tingkat partisipasi masyarakat. Dalam pembahasan ini akan di jabarkan bagaimana tingkat partisipasi masyarakat geosite lambah sembalun dalam mengambkan pariwisata halal. Pada dasarnya pengembangan pariwisata di Geosite Lembah Sembalun merupakan berbasis masyarakat (Zaini, 2019). Perencanaan pariwisata saat ini lebih fleksibel, responsive dan berbasis masyarakat serta kofrehensif (Ritchie, 1988; Simmons, 1994; Tosun \& Jenkins, 1996), sehingga pengembangan pariwisata tidak harus sifatnya top down.

Masyarakat Geosite Lembah Sembalun memiliki partisipasi yang tinggi. Mereka terlibat dari perencanaan, pengelolaan dan pengontrolan. "Kita sudah mulai melakukan perencanaan sejak tahun 2010 melakukan survei untuk pembukaaan jalur dan kemudian resmi di buka tahun 2015 (informan 8, pengelola bukit pegasingan desa sembalun)". Masyarakat memiliki ruang dan kesempatan yang sama dalam pengembangan pariwisata sehingga ini berdampak baik terhadap kesejahteraan masyarakat lokal (Mitchell \& Reid, 2001). Partisipasi ini merupakan pola partispasi spontan (spontaneous) (Tosun, 1999) memilik ketegori yang tinggi dalam ketegori partisipasi (Arnstein, 1969) dan ini merupakan interaktif partisipasi dan perencanaan berasal dari komunitas itu sendiri (Pretty, 1995). Dalam pembukaan objek wisata, pengelolaan aminitas yang ada di Geosite Lembah Sembalun berasal dari kemaun dan kesadaran sendiri begitu juga dalam pengemplikasian nilai - nilai lokal dalam praktik kepariwisataan khususnya menyiapkan pelayanan yang ramah terhadap wisatawan muslim dan pembuatan awig - awig sebagai aturan lokal. Namun dari sisi branding dan positioning sebagai halal honeymoon destination, masyarakat sama sekali tidak dilibatkan sehingga ada miskomunikasi dalam implementasi pariwisata halal di Geosite Lembah Sembalun. "Tidak ada keterlibata kan itu. Kalau halal tourism sama sekali tidak dilibatkan perencanaannya baik yang dilombok secara umum mereka tidak dilibatkan. Itulah kemudian yang menyebabkan miskomunikasi, tidak perankan" (akademisi pariwisata sembalun).

\subsection{Partisipasi masyarakat dalam pengembangan pariwisata halal}

Pada kategori yang terakhir ini terbentuk dari 5 tema yang dihasilkan dari analisis konten yang menjadi gambaran bagaimana partisipasi masyarakat dalam pengembangan pariwisata halal. Tema yang dihasilkan dari analisis konten adalah homestay, trekking organizer, atraksi, TIC dan ancillary/kelembagaan. Masyarakat memiliki partisipasi yang tinggi pada 5 tema yang muncul ini. Masyarakat lokal melihat opportunity usaha yang bisa mereka kelola dalam mendukung pengembangan pariwisata halal di Geosite Lembah Sembalun. Skill yang mereka dapatkan dari pengalaman, pengetahuan dari sumber lainya menguatkan motivasi mereka dalam berusaha homestay sebagai usaha jasa pelayanan (Saufi, 2013; Saufi et al., 2014). Kemampuan masyarakat dalam berkreatifitas untuk menjadikan kamar rumah mereka menjadi homestay merupakan pendukung pengembangan pariwisata, homestay adalah salah satu produk pariwisata yang di kelola masyarakat (Ernawati, N. M., Sanders, D., \& Dowling, R., 2019). 


\subsection{Kendala dalam Proses Analisis Konten}

Analisis konten merupakan analisis yang sangat mendalam karena setiap kata, kalimat hingga paragraf diinterpretasikan dengan sangat teliti. Makna-makna eksplisit yang disebutkan oleh informan dapat dengan mudah diketahui melalui metode analisis konten. Maka dari itu, pola pengembangan pariwisata halal berbasis masyarakat di Geosite Lembah Sembalun dapat dijelaskan secara detail dan sistematis. Hasil dari analisis ini juga didapat langsung dari data tanpa perlu memaksakan praduga perspektif teoritis seperti yang disebutkan oleh Moldavska \& Welo (2017).

Namun proses analisis konten pada penelitian ini terkandala oleh waktu karena dalam proses analisis membutuhkan yang sangat lama agar mendapatkan hasil. Tahapan tersulit pada analisis konten adalah menggabungkan hasil kode - kode yang didapatkan dengan jumlah yang banyak untuk membentuk tema dan kategori yang sesuai. Pada saat yang bersamaan peneliti harus mempelajari dan memahami teori-teori yang digunakan secara mendalam dan memperbanyak referensi agar dapat melakukan proses analisis data. Kuckartz (2014) menjelaskan bahwa pada analisis konten, semakin banyak berorientasi pada teori, semakin luas pengetahuan peneliti, semakin fokus pertanyaan penelitian, dan semakin spesifik hipotesis yang ada, maka semakin mudah untuk berpindah dari kode ke kategori.

\section{KESIMPULAN}

Penelitian ini adalah penelitian untuk membangun pola pengembangan pariwisata halal berbasis masyarakat di Geosite Lembah Sembalun dengan menggunakan metode analisis konten kualitatif. Hasil analisis konten pada pola pengembangan pariwisata halal berbasis masyarakat di Geosite Lembah Sembalun didapatkan dari proses analisis melalui pengkodean, mengelompokkan kode - kodenya menjadi tema/sub-tema dan kategori. Tema dan kategori dihasilkan dari analisis open dan axial coding. Analisis konten yang dilakukan pada artikel ini menghasilkan 3 kategori dan 11 tema yang saling berhubungan.

1. Dampak teoritis

Penelitian ini mengmbangkan beberapa hasil penelitian sebelumnya. Penelitian ini mengkonfirmasi hasil penelitian Bengsston (2016). Temuan dalam penelitian itu adalah data penelitian kualitatif dapat diperoleh dari wawancara, obesrvasi, foto dan dokumntasi. Salah satu metode dalam analisisnya adalah analisis konten. Proses melakukan analisis konten terdiri dari decontextualization, Recontextualization, Categorization dan Compilation. Untuk menemukan hasil maka perlu dilakukan tahap - tahap diatas untuk mendapatkan tema/sub-tema dan kategori.

Penelitian ini juga mengkonfirmasi penelitian Downe-Wombolt (1992) yang mengemukakan bahwa dalam analisis konten memiliki kelibihan dalam menjaga kehilangan banyak informasi dari data asli. Analisisi konten juga mampu mengurangi dana penelitian karena analisis konten bisa dilakukan oleh satu peniliti. Namun kekurangan dalam analisis konten adalah waktu. Dengan cara mengkoding data untuk mendapatkan hasil, ini memakan waktu yang banyak untuk melakukan koding.

Selain itu penelitian ini juga mengkonfirmasi penelitian (Elo, et al, 2014) bahwa kepercayaan dari hasil analisis konten tergantung pada ketersediaan data yang kaya, kesesuain, dan tersaturasi dengan baik. Oleh karena itu, pengumpulan data, analisis, dan pelaporan hasil berjalan beriringan. Meningkatkan kepercayaan analisis konten dimulai dengan persiapan menyeluruh sebelum penelitian dan membutuhkan 
keterampilan lanjutan dalam pengumpulan data, analisis konten, diskusi kepercayaan, dan pelaporan hasil. Kepercayaan pengumpulan data dapat diverifikasi dengan memberikan detail yang tepat tentang metode pengambilan sampel dan deskripsi peserta.

2. Dampak manajerial

Penelitian ini secara manajerial berpengaruh terhadap para akademisi. Penelitian ini tentunya memperkaya kajian tentang kepariwisataan khususnya penelitian tentang pariwisata dengan pendekatan analisis konten. Penelitian ini tentunya juga berperangruh kepada masyarakat dan pemerintah. Hasil analisis konten ini menunjukkan tingginya peran serta masyarakat dalam pengembangan pariwisata halal. Untuk menjadi destinasi pariwisata halal yang baik maka pemerintah perlu memfasilitasi pelatihan dan workshop kepada masyarakat gesoite lembah sembalun.

\section{Keterbatasan dan Saran penelitian}

Penelitian itu tentang analisis konten pada pola pengembangan pariwisata halal berbasis masyarakat Geosite Lembah Sembalun. Metode penelitian ini bisa di gunakan dalam skala yang lebih luas dalam mengkaji pengembangan pariwisata halal berbasis masyarakat. Variabel yang muncul pada analisis konten ini bisa dijadikan sebagai bahan penelitian selanjutnya dengan menggunakan metode analisis konten laten analisis.

\section{Acknowledgements}

Saya berterima kasih kepada Menteri Pemuda dan Olahraga yang telah memberikan saya kesempatan untuk melanjutkan pendidikan saya. Ini sangat membantu saya untuk melanjutkan pendidikan di pascasarjana dan terlibat dalam komunitas dan pemuda brilian untuk meraih kesuksesan. Dan saya juga berterimakasih khusus kepada semua pembimbing yang membimbing saya selama studi ini, keluarga saya, semua orang yang terlibat dalam studi ini dan semua teman yang selalu mendukung saya.

\section{DAFTAR PUSTAKA}

Abdillah, F., Damanik, J., Fandeli, C., \& Sudarmadji. (2015). Perkembangan Destinasi Pariwisata Dan Kualitas Hidup Masyarakat Lokal 31(2), 339-350

Arnstein, R. S. (1969). A ladder of citizen participation. Journal of the American Institute of Planners, 35, 216-224.

Battour, M., \& Ismail, M.N. (2016). Halal tourism: Concepts, practises, challenges and future, Tourism Management Perspective, 19 (2016) 150-154.

Battour, M., Ismail, M.N., \& Battor, M. (2010). The Impact of Destination Attributes On Muslim Tourist's Choice, International Journal Of Tourism Research Int. J. Tourism Res. 13, 527-540

Bagus, R.U.I.G. (2011). Analisis Siklus Hidup Destinasi Pariwisata Bali: Kajian Ekonomi Pariwisata Terhadap Destinasi.

Bengtsson, M., (2019). How to plan and perform a qualitative study using content analysis, NursingPlus Open, 2 8-14. DOI : http://dx.doi.org/10.1016/j.npls.2016.01.001

Berg, B. L. (2001). Qualitative research methods for the social sciences. Boston: Allynand Bacon.

Butler, R.W. (1980). The Concept of a Tourism Area Cycle of Evolution: Implications for Management Resources. The Canadian Geographer, XXIV(1), pp. 5-16. 
Butler, R.W. (2011), Tourism Area Life Cycle, Contemporary Tourism Reviews, Series Editor : Chris Cooper, Oxford : Goodfellow Publishers Limited.

Bungin, Burhan. (2012). Analisis Data Penelitian Kualitatif. Jakarta: Raja Grafindo Persada.

Burnard, P. (1995). Interpreting text: an alternative to some current forms of textual analysis in qualitative research. Social Sciences in Health, 1, 236-245.

Catanzaro, M. (1988). Using qualitative analytical techniques In: N. F. Woods, \& M. Catanzaro (Eds.), Nursing: research theory and practice (pp. 437-456). St. Louis: The CV Mosby Company.

Chaiboonsri, C., \& Chaitip, P. (2008). A Structural Equation Model: Thailand's International Tourism Demand for Tourist Destination. Annals of the University of Petrosani, Economics, 8(1), 65-94.

Charmaz, K. (2006). Constructing Grounded Theory: A Practical Guide through Qualitative Analysis. London: Sage Publications.

Demartoto., A. (2018). Strategi Pengembangan Obyek Wisata pedesaan Oleh Pelaku Wisata Di Kabupaten Boyolali. Universitas Surakarta. Solo.

Dinas Kebudayaan dan Pariwisata NTB. (2020). Kawasan Strategis Pariwisata Nasional. Available online from: http://www.disbudpar.ntbprov.go.id/kawasanstrategis/kawasan-strategis-pariwisata-nasional-kspn/ [Accessed September 10, 2020].

Downe-Wambolt, B. (1992). Content analysis: method, applications and issues. Health Care for Women International, 13, 313-321.

Ernawati, N. M., Sanders, D., \& Dowling, R. (2017). Host-Guest orientations of community-based tourism products: A case study in Bali, Indonesia. International Journal of Tourism Research, 19(3), p. 367-382.

Elo, S., Kääriäinen, M., Kanste, O., Pölkki, T., Utriainen, K., \& Kyngäs, H. (2014). Qualitative content analysis: a focus on trustworthiness. SAGE Open, 4.

Elo, S., \& Kyngäs, H. (2007). The qualitative content analysis process. J Adv Nurs., 62(1), 107-115.

Eriyanto. 2011. Content Analysis: Introduction to Methodology for Communication Studies and Other Social Sciences. Jakarta: Kencana Prenada Media Group.

Henderson, J.C. (2010). Islamic Tourism Reviewed, Tourism Recreation Research, 34(2), pp. 207-211, DOI: 10.1080/02508281.2009.11081594

Indonesia Muslim Travel Index (2019). MasterCard-CrescentRating Indonesia Muslim Travel Index, Jakarta : Pew Research

Jaafar, M., Jaafar, M., Shah, A.O., \& Marzuki, A. (2014). Geopark Ecotourism Product Development: A Study on Tourist Differences, X (11).

Jamal, B. T. and Getz, D. (1995). Collaboration Theory and Community Tourism Planning. Annals of Tourism Reseurch 22 (1): 186-204.

Jennings, G. (2011). Tourism Research (Vol. Second Edition). Australia: Wiley Australia Tourism Series.

Kanom, \& Zazilah, A. N. (2019). Strategi Pengembangan Pariwisata Berbasis Masyarakat Di The Mandalika Kuta Lombok. Media Bina, XIV(4), 2509-2524.

Keogh, B. (1990). Public Participation in Community Tourism Planning. Annals of Tourism Research 17 449-65.

Klenke, K. (Ed.). (2008). Qualitative research in the study of leadership. Emerald group publishing.

Kodir, A., Karim, A., \& Paksi, C. D. K. (2019). Current Issues of Halal Tourism. Case Study in Japan. 320 (Icskse 2018), 13-18. https://doi.org/10.2991/icskse-18.2019.2 
Kondracki, N. L., Wellman, N. S., \& Amundson, D. R. (2002). Content analysis: Review of methods and their applications in nutrition education. Journal of nutrition education and behavior, 34(4), 224-230.

Krippendorff, K. (2004). Content analysis: an introduction to its methodology. Thousand Oaks, California: Sage Publications Inc.

Kurniawati, E., Hamid, D., \& Hakim, E., (2018). Peran Masyarakat Dalam Perencanaan dan Pengembangan Desawisata Tulungrejo Kecamatan Bumiaji Kota Batu. Jurnal administrasi Bisnis (JAB) Vol. 54 (1)

Kuckartz, U. (2014). Qualitative text analysis: A guide to methods, practice and using software. Sage.

Mitchell, E.R., \& Reid, D.G. (2001). Community integration: Island tourism in Peru, Annals of Tourism Research 28(1):pp. 113-139; DOI: $\underline{10.1016 / S 0160-}$ 7383(00)00013-X

Moleong, L.J. (2018). Metodologi Penelitian Kualitatif. (Edisi revisi. Cetakan ketiga puluh delapan). Bandung : PT. Remaja Rosdakarya.

Moleong, L.J. (2011). Metode Penelitian Kualitatif, Edisi Revisi. Bandung: PT. Remaja Rosdakarya.

Moldavska, A., \& Welo, T. (2017). The concept of sustainable manufacturing and its definitions: A content-analysis based literature review. Journal of Cleaner Production, 166, 744-755.

Nurdiansyah, A. (2018). Halal Certification and Its Impact on Tourism in Southeast Asia: A Case Study Halal Tourism in Thailand. KnE Social Sciences, 3(5), 26. https:// doi.org/10.18502/kss.v3i5.2323

Patton, M. Q. (2002). Qualitative, research \& evaluation methods. Thousand Oaks, California: Sage publications Inc.

Ritchie, J. R Brent (1988). Consensus Policy Formulation in Tourism: Measuring Resident Views Via Survey Research. Tourism Management 9 (3): 199-212.

Polit, D. F., \& Beck, C. T. (2012). Nursing research: Principles and methods. Philadelphia, PA: Lippincott Williams \& Wilkins.

Saufi, A., O'Brien, D., and Wilkins, H. 2014. Inhibitors to host community participation in sustainable tourism development in developing countries. Journal of Sustainable Tourism, 22:5, 801-820, DOI : 10.1080/09669582.2013.861468.

Simmons, D. G. (1994). Community participation in tourism planning. Tourism Management, 15, 98-108.

Schreier, M. (2012). Qualitative content analysis in practice. Thousand Oaks, CA: Sage.

Tosun, C. (1999). Towards a Typology of Community Participation in the Tourism Development Process, Anatolia: An International Journal of Tourism and Hospitality Research, 10:2, 113-134, DOI: 10.1080/13032917.1999.9686975

Tosun, C. and Jenkins, C. L. (1996). Regional Planning Approaches to Tourism Development: The $\quad$ case of Turkey. Tourism Management 17 (7): 519-531

Pretty, J. (1995). The many interpretations of participation. Focus, 16, 4-5.

Wann-Hansson, C., Hallberg, I. R., Klevsgård, R., \& Andersson, E. (2005). Patients'experiences of living with peripheral arterial disease awaiting intervention: a qualitative study. International Journal of Nursing Studies, 42, 851-862.

Zaini, M. (2019). Pengembangan Pariwisata Halal Berbasis Masyrakat Untuk Meningkatkan Kesejahteraan, Thesis. 
Disbupdar. (2010). Kawasan Strategis Provinsi Nusa Tenggara Barat. Diunduh 28 November 2020 dari http://www.disbudpar.ntbprov.go.id/kawasanstrategis/kawasan-strategis-provinsi-nusa-tenggara-barat/

Halallivingthailand. (2014). Muslim Friendly Places to Stay. Diunduh 28 November 2020 dari http:/ / halallivingthailand.com/muslim-friendly-places-to-stay/ 